\title{
The Challenge of Linguistic Diversity and Pluralism: The Tier Stratification Model of Language Planning in a Multilingual Setting
}

\author{
Beban Sammy Chumbow \\ University of Yaounde 1 and \\ Cameroon Academy of Sciences \\ Cameroon
}

\section{Introduction}

Research crystallized by UNESCO leads to the observation that contrary to popular opinion, multilingualism is the norm in human societies and mono-lingualism an exception. Most countries of the world are multilingual. There are over 6600 languages in the world and about 2086 in Africa (Ethnologue 2009). Africa is the most linguistically diversified continent. All African countries are multilingual in varying degrees; from two or three languages in Lesotho, Swaziland, Rwanda and Burundi to over 450 in Nigeria (Ethnologue 2009)

It is also now axiomatic that multilingualism is not an obstacle to development but merely a challenge to policy formulation and implementation in the service of national development. The challenge of nationalism throughout history and more especially in the present millennium is to build a strong economically viable pluralistic nation from ethnolinguistic diversity. In line with UNESCO's position in favour of the maintenance of linguistic and cultural diversity (UNESCO 2003a), we motivate propose and justify a Tier Stratification Model of Language Planning that seeks to guarantee nationalism and pluralism over a foundation of a vibrant ethno-linguistic identity. The model seeks to make it possible for languages to be maximally utilised in the public sphere, such that each language community can conserve, preserve and maximise the development of its ethno-linguistic identity and ensure the optimal use of its language at some level(s) of the public sphere while participating fully in the social, economic and political life of the nation.

\section{Linguistic diversity and ideology paradigms}

Recent scholarship on linguistic diversity and multilingualism has been focused on language endangerment and language maintenance. Languages that are functionally vibrant and full of vitality may become endangered by losing their vitality as a result of a conjuncture of social, economic, political and linguistic factors and go through varying phases of attrition or progressive weakening resulting ultimately in language loss or language death. (See for instance Fishman 1968, Brezinger 1992, 2007, Mackey 1997, 
Grenoble and whaley 1998, Nettle and Romaine 2000, Mkude 2001, Crystal 2000, Mufwene 2001,2004, Batibo 2005 and Chumbow 2009 and 2011a among others). To prevent endangered languages from dying, appropriate measures must be taken to ensure their maintenance by way of revitalisation or the process of re-enforcing their vitality ( Cantoni 1965, Landwear 1990, Fishman 1991, 2001a,b, Romaine 2002,UNESCO 2003a, Chia 2006, Grenoble and Whaley 2006, Skutnabb -Kangas 2011, Kan Yagmur and Ehala 2011, Zaidi 2011, Ojongkpot 2012 among others).

Not everyone accepts the virtues of maintaining and cultivating linguistic diversity by undertaking a systematic implementation of revitalisation processes to ensure linguistic diversity and multicultural pluralism. As mentioned in Chumbow 2009, two conflicting ideological positions arise with respect to language diversity and language maintenance which we characterise below:

\subsection{Nation building by way of assimilation}

This is an ideological paradigm which favours the replacement of minority languages and cultures by a majority dominant language and culture. Linguistic and cultural assimilation is a process whose finality (within the context of a hidden or open agenda), is the loss or death of the minority languages and cultures, usually within the space of three generations. Underlying the paradigm of linguistic and cultural assimilation is what Gogolin1994 (cited by Benson 2011) calls the monolingual habitus; that is, the (un)conscious belief in the uniformity of languages and cultures in a nation state or a one nation one language credo.

Cultural assimilation may be conscious and planned, and therefore ideological. It may be unconscious and unplanned in which case it cannot be said to be ideological. Cultural assimilation whether ideological or not, is the result of the unfavourable balance of power against the minority language and culture. The dominant language and culture usually assimilates the weaker language, where dominance is determined by such factors as the prestige status of the language, the number of valorising functions (economically viable domains in which the language is used), etc. (See interalia, Chumbow 2008).

From the ideological perspective, cultural assimilation may be and is often used as an instrument of power to ensure the hegemonic domination of a cultural group by another or as an instrument to counter linguistic diversity and multiculturalism. Whereas cultural assimilation as an instrument of power may be dismissed as an agency to impose cultural and linguistic imperialism, the instrumentalisation of cultural assimilation to counter cultural and linguistic diversity is rationalised by the assertion that multilingualism and multiculturalism are sources of socio-economic inequalities. Some proponents and adepts of linguistic and cultural assimilation rationalise their position by the assertion that the assimilation of cultural minorities by the cultural majority is in reality, doing the former a favour, because the minority now can join the majority group and cease to be stigmatised and disadvantaged as a minority group. Thus, ideologically, assimilation is the instrument by which multilingual and multicultural communities can become monolingual and mono-cultural voluntarily or involuntarily as an outcome of cultural and linguistic imperialism. 


\subsection{Nation building by way of pluralism}

This is an ideological paradigm which seeks to maintain and develop each linguistic and cultural heritage within the nation-state as a core consideration in the enterprise of nationalism and nation building. Such an ideology, naturally favours linguistic diversity, multilingualism and the pluralism of cultures.

As underscored in Chumbow 2010b and 2011a, pluralism is patently the more dominant paradigm in the face of UNESCO positions in favour of linguistic diversity and cultural pluralism (UNESCO 2003a, b, c) as well as the African Union's Charter of Cultural Renaissance (AU 2006a and the Language Plan of Action for Africa (AU 2006b).

\subsection{Arguments in favour of linguistic diversity and pluralism}

If the UNESCO's position enjoys an ascendency that results in the dominance of the Pluralism paradigm which is fast becoming the object of a global agenda, it is precisely because of the intrinsic appeal of favourable fundamental arguments of a factual nature. Justification for cultural pluralism comes first from the incontrovertible facts of linguistic and cultural diversity. There are also independent arguments in favour of ensuring the maintenance of each existing language and culture within the nation- state as opposed to eliminating multilingualism and multiculturalism by the instrumentality of ideological cultural assimilation and linguistic genocide. These are discussed in the UNESCO articles on linguistic diversity as well as in most of the articles on revitalisation cited above. They have been discussed in detail in Chumbow (2009) but will be summarised briefly here in view of their relevance to subsequent discussion of our model of language planning for a multilingual setting.

- Multilingualism is the norm and monolingualism, the exception, globally. (Chumbow 2009).

- The languages of a nation are its natural resources (on the same level as its cocoa, coffee, gold, diamond or petroleum, etc). Like all natural resources, they have to be (planned, developed) exploited in order to be effectively and profitably used for national development. (Chumbow 1987).

- The co-existence of two or more languages is rarely in itself the cause of tension, conflict, disunity and war. On the contrary, historical evidence shows that it is economic, political and religious factors that cause conflict, tension and war (Fishman 1986, Baker 2003).

- Language is a historical heritage and is consequently a repository of the history of humanity. If one language disappears, a world vision of mankind is lost and the world is the poorer for it ( UNESCO 2003 a).

- Language is an element and a vector of culture. (Nettle and Romaine 2002:114). The loss of a language amounts to the loss of irreplaceable cultural monuments.

- Language is an intimate means of personal identity. Language loss amounts to a loss of identity (Fishman 1998).

- Language is a right; a human right of the same level of importance as all other inalienable human rights. All languages have the right to be developed and used by those who speak them for their own development. All forms of linguistic discrimination should therefore be fought and countered (Skutnabb-Kangas and Phillipson 1995). 
These and many other arguments have led UNESCO (2001 and 2003abc) to take position in favour of the conservation of linguistic and cultural diversity. To this effect, the year 2001 was declared the year of the mother tongue in order to focus on the importance of the first medium of expression acquired in a natural setting and used by the human genus to express his/her ego and innermost thoughts.

\subsection{Linguistic diversity and language management}

Linguistic diversity and multiculturalism may be desirable and perhaps inevitable as indicated above, but it must be admitted that this situation is inherently prone to a number of problems real, potential or virtual. Ethno-linguistic identities if not channelled and bridled by a spirit of nationalism may become the source of misguided ethno linguistic loyalties that undermine nationalism occasioning dissention, tension and conflict resulting eventually in what Calvet 1998 has called ' les guerres des langues' (the war of languages). However, as has been pointed out by Fishman1986 such 'language wars' (where they surface) have little to do with language per se but result from the mismanagement of ethno linguistic diversity and multiculturalism. In other words, language related conflicts are ultimately a consequence of the social, economic and political inequalities that characterise and polarise ethno linguistic communities within the nation- state

The proper management of languages in a multilingual setting in accordance with well known policy principles is therefore indispensable in stemming the potential tide of ethnic polarisation within the nation's fabric and ensuring linguistic rights, national integration and national development of all the different communities.

We propose, characterise and motivate below, a model for language planning and management in a multilingual situation..

\section{The tier stratification model}

Drawing from Jurgen Habermas's concept of the 'public sphere' (Habermas 1965), we adopt and adapt the concept (public sphere) in the context of language planning for national development in a multilingual pluralistic nation-state. The nation is conceived as the Public Sphere which is bifurcated into the private realm and the public realm (each responding to similar or different sets of micro and macro language planning activities) as summarised in the diagram below.

\subsection{Public sphere}

All languages of the nation-state belong to the public sphere. This underscores the tenet of pluralism and the need to ensure and guarantee a place in the sun for each ethno-linguistic community in a pluralistic national community.

\subsection{Private realm}

All languages indigenous to the nation belong to and make maximal use of the private realm. Foreign languages that do not have mother tongue speakers within the nation-state do not belong to the private realm but those that do, belong. Thus English in South Africa will belong to the private realm (as well as the public realm) whereas in Lesotho, it will 
belong only to the public realm. The private realm is characterised essentially by the identity function of language as a mother tongue of those who acquire and use it as a first language.

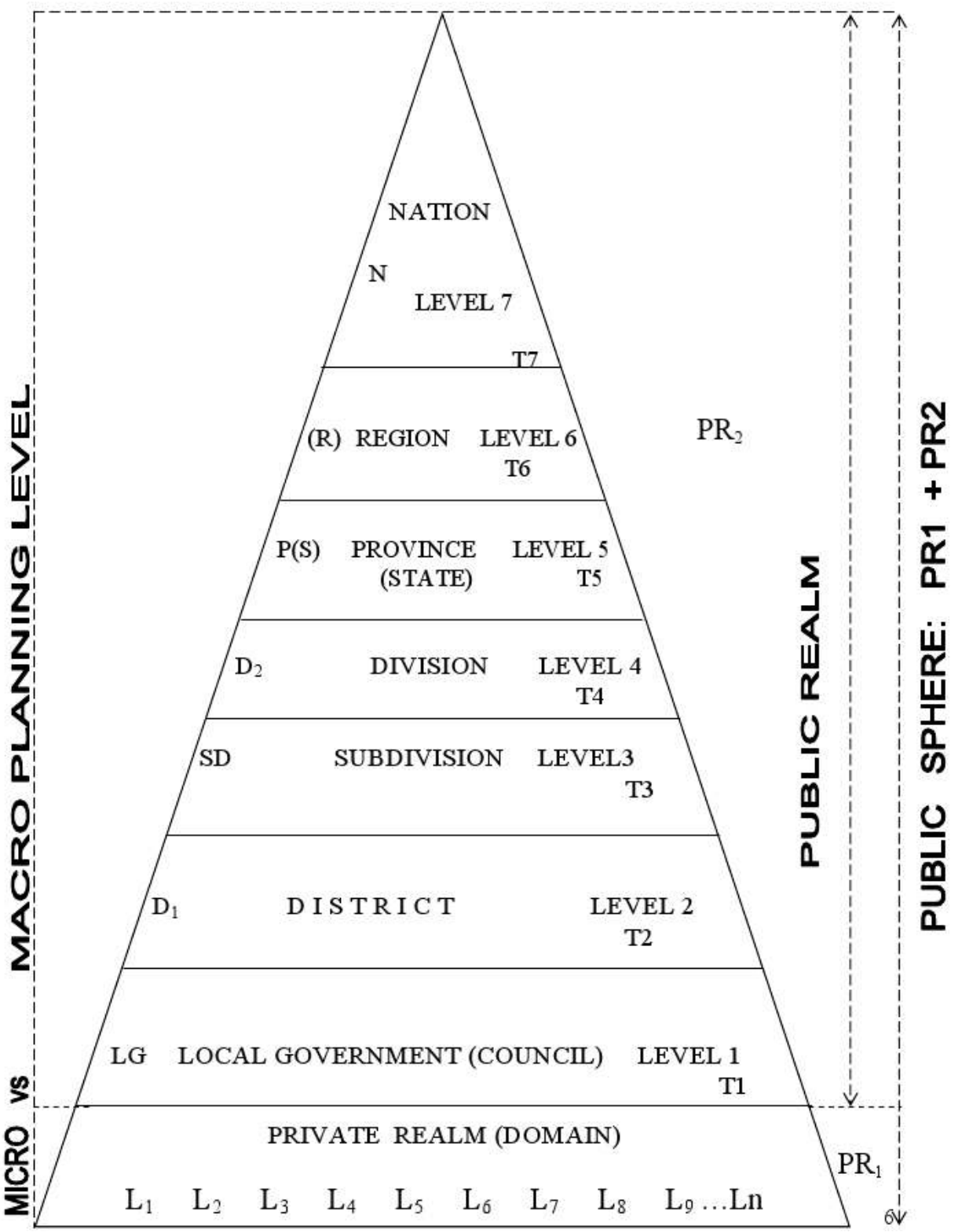

Key: L= Language; $\mathrm{Ln}=$ any number of Languages; $\mathrm{T}=\mathrm{Tier}$

Fig. 1. Tier Stratification Model of Language Planning in the Public Sphere 


\subsection{Public realm}

Some languages of the Private Realm along with exoglossic or foreign languages required as languages of interaction with the global community, (which may or may not belong to the private realm), are selected to constitute languages of the Public Realm

\subsection{Public sphere and the dialectic between the public realm and the private realm}

After a general definition of the public sphere and the private and public realms, it is important to clearly articulate here, for the purpose of operationalisation of terms, the concept of public sphere within this model and the dialectic relationship between the private realm and public realm as components of the Public Sphere

The public sphere in this paradigm is the aggregation of the private and public realms. Recall that grosso modo, the languages of the private realm include all the ethno-linguistic community languages and languages of the public realm are those selected to play are significant role in education or administration etc. at any of the administrative tiers or levels (local government, provincial or regional, state or national levels etc...see the diagram). The private realm does not mean an unimportant realm but rather it constitutes the foundation or base on which the languages of the public realm are firmly grounded. This underscores the fact that the discourse of national development in the public realm or at the national level, must take into consideration the multilingual and multicultural realities at the base or private realm. Put differently, in the public sphere or national territory, policy for the mega language(s) that function as official languages, should be inextricably linked (by planned policy) to the reality of the ethno-linguistic diversity at the base. Ultimately, there should be a bidirectional flow of information from the base to the top and vice versa, or from the official and national language(s) to and from the community languages etc. The essential concern here is that information and development relevant knowledge available in the public realm (disseminated in the official or national languages) should ultimately be made available to the private realm by the use of community languages which are better known and understood by the local populations.

In this way, the fruits and by-products of development will be shared by the national community thus eliminating the present state of affairs characterised by the marginalisation and exclusion of the rural communities whose community languages are presently not involved in the national development discourse.

The public sphere in relation to tier stratification is made up of the tiers of recognised administrative units plus one (the additional tier being the fundamental tier of the private realm). Thus, the tiers vary from country to country, depending on the core administrative units recognised by the nation (from local government units, or municipalities (councils, counties, etc) to provinces or states. The private realm is the basic or fundamental tier of the home or community where every language is spoken as a mother tongue and means of ethno-linguistic community identity and the other tiers belong to the public realm where language use is essentially intended to assure inter group communication beyond the home as illustrated in the above diagram (Fig 1).

Language planning at the public realm is at the macro- planning level. The number of tiers in the public realm is equal to the number of state recognised administrative units. 
This underscores the fact that good governance in a pluralistic state presupposes decentralisation in consonance with boundaries of natural affinities determined by cultural bonds and /or geographical contiguity. Policy at the public realm aggregates and considers situations at the base, ensuring that local (rural ethno linguistic) communities are not marginalised.

\section{Language planning in the public sphere}

In section 1 above, is asserted the fact that a major threat to pluralism in multilingual communities is language endangerment leading to attrition, assimilation, language loss and language shift. As underscored in Chumbow 2009, " in any linguistic contact situation in a multilingual setting, the default tendency is the 'law of the jungle' or survival of the fittest. The mega languages which are functionally dominant and powerful tend to gradually and inexorably 'consume' the smaller languages if left alone. Therefore, acceptance of a policy of pluralism by way of a credo in linguistic diversity in the enterprise of nation building ipso facto entails a commitment to language planning to ensure revitalisation of threatened, less dominant endangered languages and revalorisation mechanisms to ensure language maintenance i.e. the maintenance of inherent or acquired vitality of all languages of the public sphere. This has led to an upsurge in the development and implementation of language revitalisation and language maintenance mechanisms, principles and techniques especially since Fishman 1991 and UNESCO 2003a. This, in turn, has given rise to what I may conveniently call counter- endangerment activities and counter endangerment scholarship in language planning.

All of these endeavours clearly underscore the need and significance of language planning in a multilingual setting. While language planning has a long history of existence and vibrant activity, UNESCO's recent focus on linguistic diversity and its counter endangerment posture has given the enterprise of language planning a new impetus and today, scholarship in language planning stands in need of effective models that take into consideration the facts of linguistic situations (the multilingual reality and endangerment) and national objectives.

\subsection{Macro - Planning level}

Within the Tier Stratification model, Language Planning at the Macro-Planning Level (Ma PL) involves taking measures of status, corpus and acquisition planning (in the sense of Cooper 1989), to provide and envisage solutions to language problems of the nation-state at all levels. Ma PL covers either policy formulation or policy implementation in the (sense of Chumbow 1987) or both.

Macro-language Planning therefore takes place when both the private realm and the public realm (or any parts of the public realm) are involved. Thus a decentralised administrative unit like a Municipality or Council, Province or State (in a Federal system of governance) can undertake planning at its own level or administrative tier covering both ethno-linguistic communities (Private realm) of its jurisdiction and hierarchically higher tiers (Public Realm). However, generally, macro-planning is best undertaken at the national level and consecrated by a National Language Plan (of Action) resulting from a Language Charter/Law or Act (Chumbow 2010c). A national language policy based on a judicious 
consideration of the sociolinguistic variables and the aspirations for the people, a policy that is properly formulated, articulated and consecrated by a language law or language act, provides a framework of implementation in consonance with the vision and mission that the nation or state has set for itself.

The state may be expected to set up a Central Language Authority in the form of a "Language Institute, Language Centre, Language Academy or Language Board" to coordinate the implementation of the language policy or language act at all tiers as well as initiate and propose policy reviews where and when necessary. For further considerations on the terms of reference of such a structure, see Chumbow 1987 and 2010c.

Thus, the implementation of language policy previsions is carried out at the macro-planning level by effecting at least any or all of the four processes of core Language planning processes outlined in Chumbow 2010a and 2011a which we summarise below.

\subsubsection{Instrumentalisation}

This is the process that leads to the conception, formulation, promulgation or adoption of legal or executive instruments that determine the status of languages of the nation and/ or prescribe language implementation measures for language policy. Such instruments as Laws, decrees, ministerial orders and decisions constitute a legal framework for corpus planning initiatives at any level. Instrumentalisation in a more general sense, applies to all the processes initiated to increase the efficiency and adequacy of a language, especially a language with a uniquely or essentially oral tradition, to enable it better cope with its new function of acquisition and dissemination of new knowledge in science and technology, or language medium of education, for instance.

\subsubsection{Revitalisation}

This refers to measures taken to restore endangered languages to a reasonable state of vitality and to counter the process of endangerment and de-vitalisation occasioned by the absence of the intergenerational transmission of language from parents to children, etc. (See UNESCO 2003a )

\subsubsection{Revalorisation}

This involves undertaking language planning measures that add value to the inherent value of the languages. Revalorisation processes may include inter alia.

- Standardisation of languages with as yet no written standard form, through a process of o normalisation involving the provision of the language with norms of orthography, norms of grammar, etc

- Harmonisation of systems of orthography and writing for a group of related languages for which divergent systems were devised by various authors and different colonial administrations. This is frequently the case when cross border languages spread across two or more nations (with different colonial language legacies) are concerned (Chumbow1999).

- Design and production of language materials, such as primers, readers, grammars, textbooks novels, etc to enable the language assume its new function as language 
of education, language of local or regional administration etc. in national development

- Etc.

\subsubsection{Intellectualisation}

A term coined by a group of African linguists in 2003 to refer to the processes involved in accelerating the use of African language in academic and intellectual discourse (especially in academic or university settings and in the society at large) by empowering the languages in various ways such as the development of appropriate terminology in the local language for the appropriation of the avalanche of new knowledge in science and technology available in an exoglossic or foreign language of the colonial legacy (English, French Portuguese, Spanish, etc). As observed in Chumbow 2011b, the importance of all the processes involved in intellectualisation, stems from the fact that 'limiting intellectual and development-relevant discourse to languages of the colonial heritage as is presently the case, marginalises the majority of the African population whose inadequate knowledge of these languages does not allow them to participate fully in the debates which concern their welfare'.

\subsection{Micro - Planning level}

Language Planning at the Micro-Planning Level (Mi PL) involves undertaking language policy implementation measures to solve identified language-related and languagedependent problems of the ethno-linguistic communities at the Private Realm. Local or Regional governments may take decisions to develop and use one or more languages. One expects that at the Mi-PL, a Language Planning Committee (LPC) is constituted for each language and supported by the Association of the elites of the linguistic Community and other organisations such as 'Descendant Unions', Civil Society Organisations (CSO) to assist the LPC with human and material resources needed to undertake at the private realm any language planning activity (revitalisation, revalorisation, instrumentalisation and intellectualisation) to make the language apt to assume new functions (in education, communication etc. assigned to it by policy or to improve on these functions where they exist.. The Mi PL may involve some status planning decisions compatible with previsions of the language policy or law but mainly deals with corpus planning activities to give effect to status planning decisions taken essentially at the Macro-planning level.

\subsection{Maintaining the relation between the two realms}

Since, in any multilingual and multicultural pluralistic state, dominance prevails as determined by a conjunction of vitality and status conferring variables of a social, economic and political nature, we submit that Language Planning (LP) has the duty and responsibility of mediating dominance, by way of a redistribution of the vitality conferring variables so that all the languages have at least the minimum required for their vitality and survival. The point being made here is that without intervention and a judicious mediation of the variables, we involuntarily (or voluntarily?) ordain the slow death of some of the languages ultimately. This is so because as indicated above, in any language contact situation, the default process is the law of the jungle or the survival of the fittest or dominant (and powerful) languages in the power-configuration and the concomitant 
progressive weakening, attrition and / or loss of disempowered minority languages. Therefore to ensure the revitalisation and maintenance of the vitality of languages so as to enhance and maintain linguistic diversity and pluralism, it is proposed that Language Planning in a multilingual setting be governed by at least two principles: The Principle of Functional Complementarities (PFC) and the Principle of Attitude Engineering (PAE).

\subsubsection{Principle of functional complementarities}

The Principle of Functional complementarities (PFC) proposed and motivated in this section ( see Chumbow2009 for an earlier version) pertains to the domains in which minority languages are used in relation to the domains of the majority or dominant language.

The principle of functional complementarities (PFC) requires that at the level of status planning (or policy formulation), all languages of the nation-state should be ascribed their inalienable identity function (the primary function) and be allocated some other valorising functions (education/literacy, media, public administration, parliament, business/commerce, etc.) necessary to ensure and assure the vitality and maintenance of the language and its contribution to the national development enterprise in the private and public realms.

Valorising Functions are those that procure economic, social and political advantages and thereby contribute to raising the status of the language.

The claim underlying this principle is that languages which are standardised and use in several domains and economic functions have a better chance of withstanding the vicissitudes, tornadoes and tsunamis of life than those which are not. They are therefore more resistant than languages with a tenuous existence and a limited or restricted functional load. The latter are more prone to undergoing language shift and extinction than those that are assigned a variety of functions in the enterprise of national development. This is in line with similar observations made by the counter-endangerment advocacy and scholarship summarised in UNESCO 2003a.

Evidence in favour of the complementarities of functions abound. Of the (about) 286 languages of Cameroon (Ethnologue 2009), about 100 are codified and are in varying degrees of formal usage. But only about a third (35) are used seriously in some form of education in the programmes of the National Association of Cameroon language Committees (NACALCO) and the activities of the Cameroon Association of Bible Translation and Literacy (CABTAL). and these prove to the be more resilient in terms of vitality than the others whose use is essentially oral and limited to the home domain.

Recall that we have observed that commitment to linguistic diversity means acceptance of ethno-linguistic pluralism as a fundamental element in the paradigm of development. This requires the promotion of peaceful co-existence of ethno-linguistic groups of people in a pluralistic society where plurality does not entail replacement of one language by another but a recognition of the functional complementarities of all languages in a relation characterised not by mutual polarisation and enmity but by mutual cohesion and support. 
What is the motivation of the principle of functional complementarities and what is it intended to achieve? The motivation is restated here as articulated in Chumbow 2009:

- Firstly, the PFC is congruent with the objectives of pluralism and the need to develop multilingual and multicultural societies where all ethno-linguistic identities are nurtured, preserved and harnessed for national development.

- Secondly, it seeks to empower minority languages which have generally been disempowered by being left with only the identity function to boast of, leading to a situation where users choose to go straight for the dominant language of power, which guarantees economic advantages and social amenities, leading to the abandonment, endangerment and consequent shift of the minority language. In South Africa, for instance, parents and pupils reject Mother tongue school facilities because the mother tongue in the bilingual education system does not lead to any valued functions and job opportunities, unlike English and it is therefore considered a waste of time (Stroud 2001, Alexander 2001, 2005, Nkonko 2003.

- Thirdly, commitment to the PFC requires that languages share some functions, and that their users be supportive of each other and see each other as members of a team whose goal is attainment of the ideal of national development. The principle of complementarities commits all linguistic communities to some sort of vicarious responsibility for their common endeavours for national development.

- Fourthly, redistribution and sharing of valorising functions officially by this principle re-enforces the vitality of all languages including minority languages and thereby guarantees their survival and stability

\subsubsection{Domain penetration and the power of the PFC}

In another context (Chumbow 2008), we have envisaged and stated the implementation of the PFC in terms of domain penetration. In this sense, to increase, sustain and maintain the vitality of minority languages, they have to be led out of the home domain to which they are often confined to penetrate into domains hitherto reserved for the official languages, and other dominant languages (including domains of education, the media, administration, commerce, parliament, etc). Thus, while endangerment involves a language losing some of its domains as a result of domain encroachment, domain penetration is a counter-endangerment process by which a minority language gains new domains of usage. The PFC therefore triggers a process of a deliberate planning and execution of domain penetration.

It is well known that the normal distribution of power between majority and minority languages is not dependent on the intrinsic value of the languages concerned but on historical accidents, of military, political or economic power. Thus, the balance of power in favour of dominant official languages (like English and French) in the African context, is due to the unfortunate circumstances of imperialism and economic dominance since the era of colonisation (Phillipson 1995). It may also be attributed to a conspiracy ignited by the forces of globalisation in collusion with the local (African) ruling class (Mazrui 1997) or by the survival instinct of the elite class struggling to protect its monopoly in the use of the foreign languages as a source of economic and political power that excludes the masses (Myers Scotton 1993). Similarly, social, economic, ethno-cultural and political factors of dominance explain the ascendancy of the other dominant African mega languages over 
others. The PFC and Domain penetration and can redress the imbalance and its nefarious consequences of marginalisation and exclusion.

\subsubsection{Principle of Attitude Engineering (PAE)}

In the implementation of the PFC and other principles geared towards ensuring harmony in the development of the various ethno-linguistic communities in a pluralistic nation-state, the most formidable obstacle to the endeavour is the negative attitude of citizens towards the other language or towards their own language ( in preference for a foreign official language).This point has been adequately articulated in the literature and underscored by UNESCO 2003a. The ultimate question is, what can be done about negative attitudes and their negative effects on the enterprise of pluralism? As already mentioned, negative attitudes towards one's own language or towards other languages in a multilingual setting is often determined by dominance variables, for instance, the hegemonic legacy, influence and dominance imposed by years of colonial and neo-colonial imperialism that make the language of the colonial legacy or heritage the language of education, administration etc. Governments and states may be guilty of negative attitudes towards some languages of the nation as evidenced by (official) language policies that systematically marginalise and exclude speakers of minority languages in favour of the 'official' or 'national' languages.

Negative attitudes heighten vulnerability when confronted by difficulties or pressure from another language (Gardner (1985)). In the case of negative attitudes towards one' own language, one is ready to give in at the least difficulty. Similarly, if the negative attitude is towards another language, one is predisposed to be aggressive with the slightest excuse. Those with a positive attitude, on the other hand, tend to resist pressure and invoke linguistic human rights and minority rights, (etc.) to get results in favour of their language, or any language perceived to be the object of victimisation. Negative attitudes constitute a stumbling block to the acceptance of the principle of functional complementarities or the accommodation of any principles and practice congruent with sharing of functions or penetration of new domains by minority languages. This constitutes a major obstacle to the enterprise of language revitalisation and the counter-endangerment processes.

To deal with this syndrome, we propose the principle (or process) of attitude engineering (PAE) Chumbow 2009

- By attitude engineering we mean the systematic use of sociolinguistic and psycholinguistic knowledge, principles and techniques to determine attitudes of government and the speakers of various languages in a language contact situation and the use of the findings as input for the design and implementation of a programme to effect polarisation of attitudes in the direction of a desired policy outcome.

What is the rationale for the principle of attitude engineering proposed here?

Attitude engineering involves taking appropriate measures to convert negative attitudes to positive attitudes. Positive attitudes actually underlie all of the UNESCO 2003a conditions for revitalisation of endangered languages and maintenance of linguistic vitality of all languages to ensure diversity as illustrated below

- A positive attitude leads to a better predisposition to resistance of pressure. The ability for a minority language to resist domination pressure and adopt mechanisms to 
appropriate and consolidate the use of existing domains and penetrate new domains and acquire valorising functions etc, as proposed above, depends on the positive attitude of its users. A collorary of this is that a population with negative attitudes ipso facto lacks the motivation to act in favour of the maintenance of their language).

- A positive attitude (resulting from the application of the PAE) and dynamism in favour of the maintenance of the language will motivate and guarantee intergenerational transmission of the language to children and ensure that the linguistic community maximises the UNESCO (2003a) criteria conditions of 'absolute numbers of speakers' and 'the proportion of speakers of the language within the population'.

- The positive attitude and socio-economic dynamism of speakers of a language often contribute to the increase of the number of people involved in the acquisition of that language as a second language by others outside the linguistic community, thus contributing to the vehicularity of their language.

- With positive attitudes, speakers can constitute Language Planning Committees and mobilise the elites of the linguistic community to lobby for government and institutional support, ensure the production of language and literacy materials and undertake relevant documentation for the language.

- With positive results from positive attitudes, members of a linguistic community can fortify and re-dynamise their own attitudes, leading to increased positive actions and concrete achievements in the maintenance of the language's vitality. Put differently, the process of mutual re-enforcement between positive attitude, positive action and positive results produces a multiplier effect which maximizes and optimises opportunities for language use.

As mentioned above, even governments may also have an attitude problem. Another dimension of the PAE is to verify not only the attitude of linguistic minorities and the linguistic majorities but also government's attitude so as to usher in macro-level language policy changes and policy implementation actions in favour of linguistic minorities. A relevant question in this respect (among others) is whether there is a policy instrument in favour of the development and use of minority languages in key domains which linguistic communities can use as warrants for their micro-level language planning initiatives and as a basis for countering resistance from dominant groups. Relevant data for attitude engineering in language planning therefore crucially involves information on (a) the attitude of speakers of a language towards their own language(b) the attitude of speakers of other languages towards that language and (c) the attitude of government towards majority(or dominant) and minority(or less dominant) languages

A fourth dimension is that attitude engineering as a macro level (psycho-social technological) activity is intended to bring about the often vaunted but very elusive 'change of the mindset'. 'Mindset change' for an entire population is often presented as a desired social and economic necessity in the African context. It is a dilemma of contradictions that Africa and its people are endowed with natural resources of considerable variety, quantity and quality but remains eternally poor. Scholars who examine this and similar issues have come to the conclusion that what Africans need is a 'change of mindset'. Ngungi Wa Thiongo 1995 attributes the negative attitudes of Africans to education in the mother tongue in favour of English to the colonial mentality which sees English, 'the language of imperialism' as the only medium for intellectual and academic discourse. Alexander 2001 
laments this state of affairs in the following term: "How can we transform the climate of opinion so that we can shift the colonial minds from the groundless belief that only knowledge which is packaged in the languages of the colonial conquerors is worthwhile knowledge?"

Adedavoh Delanyo 2007 discussing the need for transformation in Africa to usher in the much vaunted take- off for development, states emphatically and with conviction, 'new leadership in Africa requires leaders with new mindsets'

Observations on the need for a change of mindset in Africa and elsewhere characterise much of the discourse of social sciences research. It is therefore apparent that the concept of change of mindset putatively has some validity. However, it is not clear at the moment what mindset change means or what it entails. It is as yet only a construct that must be operationalised. There is a need for theory of mindset change.

It is however, self evident that a change of attitude is a possible indicator of a mindset change in that the change of mindset inevitable has to go through or result in attitude change (resulting from attitude engineering). Ultimately, attitude engineering principles can be generalised to take care of such intractable issues as change of attitudes with respect to HIV/AIDS campaigns, etc. The concept and process of Attitude Engineering sketched above has the potential of satisfying the need for a model that can organise a structured set of actions and activities that will result in mindset shift manifested in attitude change and behaviour change in any area where attitudes are relevant and important. A discussion of these issues is beyond the scope of this paper. For the interested reader these issues are sketched in Chumbow (2008a and in Chumbow 2012 where attitude engineering is seen as part of a general model of a process of social engineering that starts with awareness of an innovation (a new mentality) and goes through phases of comprehension, knowledge, judgement, change of attitude and change of behaviour as indicators of appropriation of the new ideas, new knowledge or new mindset. Thus, attitudinal and behavioural evidence of the appropriation of a new mindset in the place of an old mindset would be prima facie evidence of a change of mindset.

\section{Case studies using tier stratification model of planning}

This section presents case studies by way of a cursory illustration of the application of the tier stratification model of language planning. To do so we outline, by way of a summary, essential requirements of the model at the policy formulation or status planning level.

\subsection{Key requirements for the application of the model}

The application of the Tiers stratification model of language planning has to take into consideration Macro-Level planning information for Language planning in the public sphere (which constitute essential elements of language policy).

1. Official (National )Language(s) in the Language Policy (OL-LAP) What languages are (can be or should be) prescribed as 'official languages' of the nation in the National language Policy? Where a language policy exists, the policy provisions have to be applied in the model; if not, language planning endeavours can provide or prescribe Official or National language(s)

2. Number of Administrative Tiers (N A T). How many (major) administrative units are there in the nation (from the Local government to provincial or state levels)? 
3. Language of Administration for the Administrative tiers envisaged in the language Policy (LAT-LAP). Are there any languages envisaged for use in official transactions and interactions at some levels or tiers of administrative units (other than the official/ national language in (1) above? It must be emphasized that it neither necessary nor desirable that a different languages be designated for different administrative tiers. In fact, for practical reasons of not overloading the individuals in the nation -state, it is desirable that several tiers be associated with one language.

4. Language in Education Policy (LiEP). The ideal language-in education policy for multilingual and pluralistic states is one proposed by UNESCO (2003b) and other international organisation such as the Council of Europe, the African Union (AU2006b), the Bamako International Symposium on Multilingualism, etc. It has been developed as the 'Mother Tongue- based Multilingual Education (MT-MLE) policy which recognises that all education should, as far as possible, be carried out in the Mother tongue as far up the ladder of education as possible along with one or more languages designated to play some function at different administrative units (council, regions or state, etc.) of the nation.(See Heugh 2006 among others). Thus, the MT-MLE is actually a Mother tongue -based bilingual or multilingual education. This is envisaged and summarised in Chumbow 2010b as Mother tongue plus a constellation of language as determined by the state's policy. The logical language combination possibilities of MTMLE are presented in (a) - (d) below with MT (Mother tongue as an obligatory constant).

a. MT+ OL: (MT+ one language constellation where the one language is the official language.

b. MT+ L2, OL: (A two languages constellation where the official is used with one language slated to be used at one or more administrative levels.

c. $\mathrm{MT}+\mathrm{L}_{2}, \mathrm{~L}_{3}, \mathrm{OL}$ : A three Languages constellation consisting of the official (or national) language and two other languages used at one or more lower level tiers or

d. $\mathrm{MT}+\mathrm{L}_{2}, \mathrm{OL}_{1}, \mathrm{O}_{2}$ : The three languages constellation may be from one lower tier language and two official languages.

e. $\quad M T+L_{2}, L_{3} \quad \ldots L_{n}+O L$. Where $L_{n}$ refers to any number of languages along with the Mother tongue and the official or national language.

5. Constraint on the number of Languages to be prescribed for Learning. Although theoretically, there is no upper limit to the number of languages an individual can learn or acquire, there are practical methodological problems with teaching too many languages as research on the identification and implementation MT-MLE shows. It is therefore necessary to limit the combination of languages in the MT-MLE to a four language learning situation; that is, a three language constellation ( $\left.\mathrm{MT}+\mathrm{L}_{1}, \mathrm{~L}_{2}+\mathrm{OL}\right)$. Thus with this constraint, we expect to have (a) MT-based bilingual education, (b) MT-based trilingual education and(c) MT-based quadrilingual education. This in effect means that the logical possible combination of languages reflected in (e) above is ruled out as a possible LiEP (even though individuals may on their own acquire and use more than four languages.

6. Assignment of economically valorising functions to ethno-linguistic community languages of the private realm by the application of the Principle of Functional Complementarities (PFC)

7. Sensitisation of Populations on issues of language and development, pluralism and the virtues of multilingualism and multiculturalism. This includes inter alia application of the Principle of Attitude engineering (PAE). 


\subsection{The tier stratification model applied to Tanzania}

Tanzania is famous for having developed and instrumentalised the use of Kiswahili as a national language alongside English, the language of the colonial legacy, to the extend that for many, Kiswahili is the only known African language of the country. However, there are about 120 ethnic community languages in Tanzania (besides Kiswahili and English) A Tier stratification language planning for Tanzania could / would be as follow:

\subsubsection{Official or National Language in the Tanzanian Language Policy}

The existing language policy position holds that Kiswahili is the national Language and used as an official language of administration at all strata and administrative tiers from the Local Government and above with English considered an official language sharing domains with Kiswahili. (The policy does not assign much of any significant functional role to the ethnic community languages).

\subsubsection{Number of administrative Tiers}

This is not important in that Kiswahili is envisaged to be used in all administrative tiers with English. However, a revision of the policy can be envisaged to enable some of the local languages of wider communication such as Sukuma, Gogo, Haya, Nyakyusa, Makonde etc. to be assigned functions at the regional levels (along with Kiswahili and English). Also, some cross border languages with a more significant population of speakers across the border such as Luo (Kenyan Border), Haya,(Burundi), Makhua (Mozambique) etc. can be developed by a Transborder language Planning Committee (Chumbow 1999) for use in both or all countries for various functions including (at least) the function of education (as part of the language -in -Education policy).

\subsubsection{Language of Administration in the various Tiers in the Language Policy(LAT- LAP)}

The public realm (in current Tanzanian policy) is conceptualised to use only one (African) national language (Kiswahili) for all the administrative units of the public realm and in all the functions and domains along with English, a partner language, i.e. a foreign language serving as official language and language of international discourse or language of globalisation.

However, the modifications suggested in 4.2. 2 above can assign the function of language of administration to some languages of wider communication in some regions of the nation (eg. Sukuma, etc.) along with the national and official languages (Kiswahili and English).

Given the facts in section 4.2 (4.2.1-3 ) above, the diagram (fig.2 above) captures the facts, representing the national level and the national-official language (Kiswahili) stretching across the entire public realm and used at all levels of administrative units from $T_{1}$ to $T_{n . .}$ Note that the official language, English parallels the national language in all functions and in this model is therefore considered a one language stratification even though two languages are involved. Indeed no stratification is involved in the use of the two languages. 
The tier stratification model applied to Tanzania

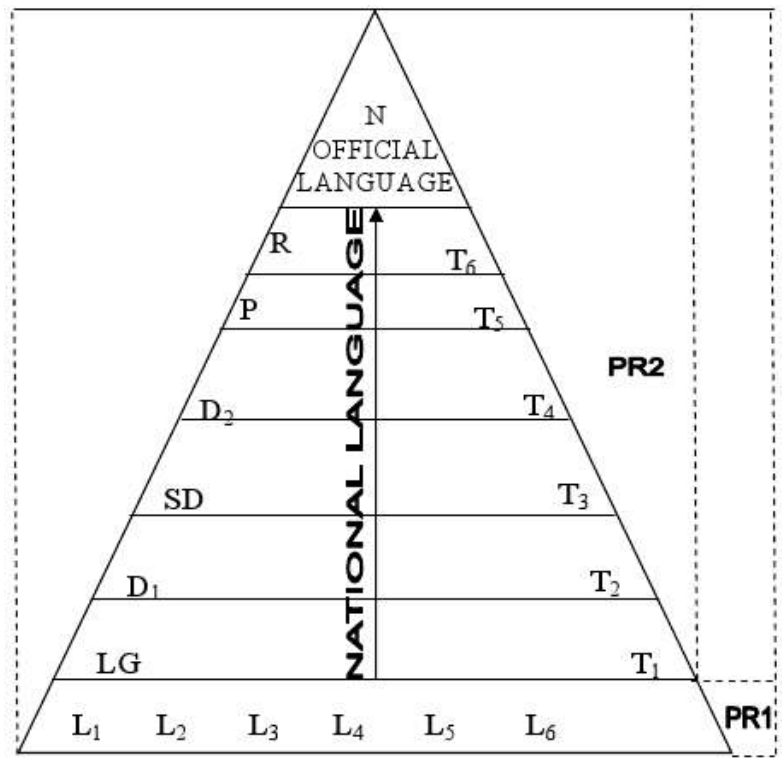

Fig. 2. One Language Stratification

\subsubsection{Language in education policy}

Contrary to the observed neglect of Ethnic Community Languages (ECLs) in Tanzania (Mkude (2001, Batibo 2005), the Tier stratification model places all these languages ( $\mathrm{L}_{1} \mathrm{Asu}$, $\mathrm{L}_{2}$ Bena, $\mathrm{L}_{3}$ Kivungu, $\mathrm{L}_{4}$ Nyamwezi, $\mathrm{L}_{5}$ Haya, $\mathrm{L}_{6}$, Makonde $\mathrm{L}_{7}$ Sukuma, ... $\mathrm{L}_{\mathrm{n}}$ ) in the private ream and micro level planning activities have the responsibility of taking appropriate measures to revitalise, revalorise, instrumentalise and intellectualise all them for use in education in the application of the MT- MLE language -in-Education policy discussed above. This leads us to language in education policy (LiEP) that favours the development and use of the about 120 ethnic community language presently neglected. We have thus envisage a trilingual education situation of $\mathrm{MT}+\mathrm{L}_{2}$ (Kiswahili) $+\mathrm{OL}$ (English). (A quadrilingual education situation is possible where some languages (Sukuma, Makonde, etc. are recognised as administrative languages at the Regional level).

\subsubsection{Constraint on number of languages in education}

The constraint in the number of languages involved in the school system is respected with generally a two language constellation $(\mathrm{MT}+\mathrm{NL}+\mathrm{OL})$ and exceptionally, in some regions , a three language constellation is possible.

\subsubsection{Assignment of valorising functions}

Beyond the identity function the ECLs are assigned at least two functions: language Medium of education and language of administration at the District/Local government 
level. This can be extended to other valorising functions by national policy. However the use of these language in education and administration at one tier reinforces the language's vitality considerably beyond the intrinsic identity function.

\subsubsection{Sensitization of the national community}

Sensitization of the national Community on the role of language in nation building and language and pluralism, especial with all stake holders including not only speakers of majority and minority languages but also the government which needs to reverse its negative attitudes to ECLs which are currently neglected in favour of Kisawhili. (See for instance Batibo1992, 2005 and Mkude 2001, Rubanza 2002).

\subsection{Tiers stratification in a situation of two or more national languages}

In this variant the nation or public sphere conceives two or more (but a limited number of national languages) to be used in the public realm in prescribed zones or regions of the country. Figure 3 below represents this variant.

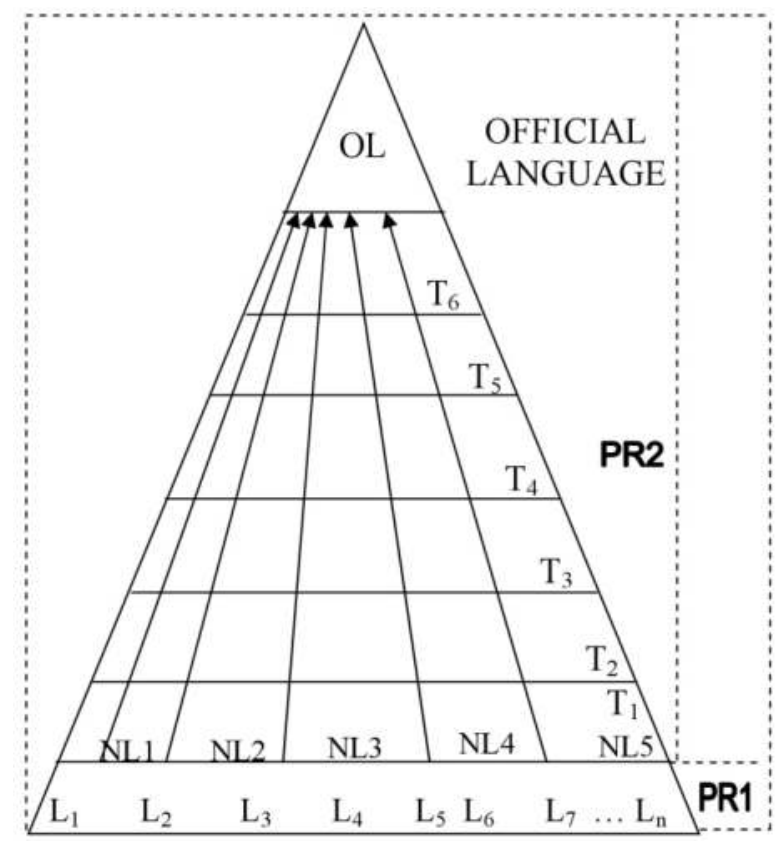

Fig. 3. Five languages stratification

On the basis of the type of analyses carried out in section 4.2 for Tanzania, Nigeria is a good candidate for such a stratification, where Hausa, Yoruba, Igbo and Fulfulde spoken by over fifteen million people each, can safely be declared the language of education and governance of the public realm in several states along with English, the official language, while each of the about 450 languages are used at the level of the private realm. Each state can then evolve a LiEP on the MT-MLE pattern using a convenient and relevant 
constellation of languages duly constrained. The practical challenges of human and material resources in the implementation of language policy are not discussed here.

These are the subject and object of discussions in the literature. See, for instance, Chumbow 1987, 2005 and Bamgbose 1991 among others.

\section{Conclusion}

This paper sought to elucidate the problematic of language planning for national development in a multilingual setting. This is anchored on an ideological paradigm that attaches premium to linguistic diversity and pluralism as the basis for nationalism, nationhood and national development in consonance with UNESCO's 2003ab position. A study of the facts of multilingualism and multiculturalism provides the background for a framework for language planning in the public sphere. The Tier Stratification Model provides for the private realm where all languages of ethno-linguistic communities are catered for at the micro planning level and the public realm where the language needs of administrative units of the nation within the public domain are managed at the macroplanning level. The model further seeks to capture the dialectic and dynamic relation that exists or should exist between the languages at the private and public realms. Given the potential problem of dominance and tension in situations of language contact and the need for a harmonic relationship of symbiosis in a pluralistic state, the Principles of Functional Complementarities and Attitude Engineering are proposed, motivated and rationalised as relevant factors in the mediation of the relation between languages of the private and public realms, in an ideal language planning model that seeks to enhance national identity while maintaining pluralism and ethno-linguistic diversity by countering endangerment and enhancing revitalisation of vulnerable and threatened minority languages.

\section{References}

Adedavor Delanyo 2007. Leading Transformation in Africa. ILF Publishers, Orlando,Florida. Alexander, Neville. 2001. "Key Issues in language policy for Southern Africa". In Trewby Richard and Sandra Fitchat (eds.) 2001.

Alexander Neville 2005 (ed.). The Intellectualisation of African Languages. The African Academy of Languages and the Implementation of the Language Plan of Action for Africa. Cape Town: PRAESA.

AU. 2006a. The Charter of the African Cultural Renaissance. Addis Ababa: The African Union. AU 2006b. Language Plan of Action for African Development. Addis Ababa: The African Union. Baker, Collins. 2003 Bilingual Education, Multilingual Matters. Clarendon, Buffalo, Toronto Bamgbose, Ayo 1991. Language and the Nation, University of Edinburgh Press.

Batibo, Herman. 1992. "The Fate of Ethnic Languages in Tanzania". In Brenzinger, M. (ed.)1992

Batibo, Herman 2005. Language and Death in Africa. Causes, Consequences and Challenges. Multilingual Matters. Clarendon. Buffalo. Toronto.

Benson Carol 2011. African languages, educational quality and the issue of parent choice. In Thornell Christina and Legere Karsten eds. North -South Contributions to African languages, Rudiger Koppe Verlag,Koln. 
Brenzinger, M. 1992. Language Death: Factual and Theoretical explorations with special reference to East Africa. Berlin \& New York: Mouton de Gruyter

Brenzinger, M 2007 Language Endangerment throughout the World. In Brenzinger ed.2007) Language Diversity Endangered (pp 9- 13). Berlin : Mouton de Gryuter.

Calvet Louis Jean 1998 Les guerres des langues, Paris, Hachette

Cantoni Gina, C (1965) 'Revitalising Indegenous Languages'.In Reyhner, Jon, Gina Cantoni, Robert, N., St Clair and Evangeline Parsons Yazzia,eds.

Chia Emmanuel 2006 Rescuing Endangered Cameroonian Languages.'In Chia E ed. African Linguistics and the Development of African Communities'.CODESRIA BOOKS, Dakar.

Chumbow, B. S. 1987. Language Planning Model for Africa. Journal of West African Languages. Vol, 2. 1987.

Chumbow, B.S. 1990. "The Mother Tongue in the Nigerian Language Policy”. In Emananjo, Nolue. (ed.). Minority Languages and Education in Nigeria. Agbor, Nigeria, 1990.

Chumbow, B.S, 1999 'Transborder languages of Africa'. Journal of Social Dynamics, No.25 ,Winter 1999 pp 51-61

Chumbow.B.S. 2005. "The language Question in National Development in Africa". In Thandika Mkandiware. (ed.). African Intellectuals: Rethinking Gender, Language and Politics in National Development. Zed Books London, and Dakar: CODESRIA.

Chumbow, B.S. 2008.Vehicular Cross border Languages and Endangerment of Minority Languages. Mediating a Symbiotic Functional Relationship. In The Bulletin of the African Academy of Languages. Vol.3, 2008

Chumbow, B.S., (2009)' Linguistic Diversity, Pluralism and National Development in Africa'. In, Africa Development, Vol. XXXIV, No 2, 2009

Chumbow B.S. 2010a. La politique linguistique de l'Académie Africaine des langues et la diversité linguistique. In Bidja Kody ( ed.) Diversité linguistique et université francophone, Paris Harmattan, 2010 .

Chumbow. B. S. 2010b. Mother Tongue -based Multilingual Education: Theory and Models. Keynote address: Forty First Annual Conference on African Linguistics (ACAL), Toronto, Canada, May 2010.

Chumbow. B.S. 2010c. Towards a Framework for Language Laws and Language charters. Keynote Address: 13th Conference of the International Association of Linguistic Law (IALL), Bloemfontein, South Africa. (Forthcoming in Conference proceedings).

Chumbow B.S. 2011a. "The African Academy of Languages and the Continental Language Development Programme." In Thornel Christina and Karsten Legere (eds). NorthSouth Contributions to African Languages. Rudiger Koppe Verlag, Koln, 2011.

Chumbow B S. 2011 b. African Renaissance and National Development in the Age of Knowledge Economy. Keynote Address: The Conference on African Renaissance, Integration, Unity and Development, University of South Africa Pretoria, September 2011

Chumbow B .S. 2012. Social Engineering Theory: A Model for the Appropriation of Innovations'. To appear in A. Lopez- Varela (ed.) Social Sciences and Humanities:

Applications and Theory Vol.2, INTECH PUBLICATIONS, RIJEKA, 2012

Cooper Robert, L 1989. Language Planning and Social Change, Cambridge University Press

Crystal, D. 2000. Language Death, Cambridge, Cambridge University Press.

Ethnologue, 2009. Ethnologue: Languages of the World, SIL, Dallas Texas 
Fishman, Joshua. 1968. "Language Maintenance and Language Shift as a Field of Inquiry". Linguistics 9:32-70.

Fishman, Joshua. 1991 . Reversing Language Shift: Theoretical and Empirical Foundations of Assistance to threatened Languages. Clevedon, UK: Multilingual Matters.

Fishman. Joshua 1999(ed.) Handbook of Languaguage and Ethnic Identity. New york, Oxford.Oxford University Press

Fishman Joshua 2001a . Maintaining Languages. Rowley, Massachusetts FishmanJoshua2001b.'Can Threatened Languages Saved? 'Reversing Language

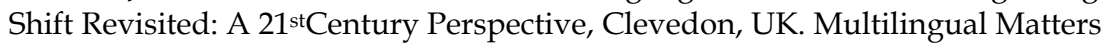

Gardener R C 1985 Social Psychology and Second Language Learning: The Role of Attitude and Motivation, London, Edward Arnold

Gogolin Ingrid.1994 Der monolinguale Habitus der multilingualen Schule. Munster: Waxmann

Grenoble Leonore and Lindsay Whaley (eds.) 1998 Endangered Languages: Current Issues and Future Prospects. Cambridge. Cambridge University Press.

Grenoble and Whaley 2006. Saving languages: An introduction to Language Revitalization. Cambridge. Cambridge University Press

Habermas Jungen 1963. Structural Transformation of the Public Sphere: An Inquiry into a category of bourgeoisie society. Frankfort

Harmon, David and Luisa Maffi. 2002. "Are Linguistic and Biological Diversity linked?". In Conservation Biology in Practice 3, 1.2002.

Heugh, Kathleen (2006). Theory and Practice- Language Education Models in Africa: Research, Design, Decision-making, and Outcomes. In Alidou, Hassana et. al.(eds). Optimizing Learning and Education in Africa: The Language Factor. A Stock Taking Research on Mother Tongue and Bilingual Education in Sub-Saharan Africa. Paris: ADEA, 138-156.

Landwear, M.L. 1990 'Indicators of Ethnolinguistic Vitality: Case Study of Two LanguagesLabu and Vanimo'. In Ostler(ed)1990. 64-72

Mackey William. 1997 'Vitalité Linguistique', in Marie-Louise Moreau (ed.), Sociolinguistique: Concept de base; Liège: Mardaga: pp 294-296.

Mazrui Ali. 1997. "The World Bank, the Language Question and the Future of African Education". Race \& Class 38 (30) 35-48.

Mkude, Daniel. 2001. "Minority Languages vs. Kiswahili in Tanzania: A painful dilemma”. In Trewby Richard and Sandra Fithat (eds.). 2001, 159-167.

Mufwene Salikoko 2001. The Ecology of Language Evolution. Cambridge. Cambridge University Press

Mufwene Salikoko 2004. Language Birth and Death, Annual Review 33, 201-222

Myer- Scotton, Carol 1993 Elite closure as a powerful language strategy: the African case. International Journal of the Sociology of Language,103, 149-163

Nettle, Daniel and S. Romaine. 2000. Vanishing Voices. Extinction of the World's languages. Oxford: Oxford University Press.

Ngugi wa Thiong'o .1995. Decolonising the Mind: The Politics of Language in African Literature. London: Heinemann.

Nkonko. Kamuangamalu 2003. “Globalisation of English and Language Maintenance and Shift in South Africa". International Journal of the Sociology of Language, 164, 65-81 
Ojongkpot, Comfort. 2012. Assessing the Degree of Language Endangerment: The case of Manyu Languages. PhD thesis, University of Buea

Ostler, N 1990 (ed.) Tongues Ancient and Postmodern.Iatiku 3, 1-2

Phillipson, Robert. 1995. Linguistic Imperialism, Oxford, Oxford University Press.

Romaine S. 2002 'The Impact of Language Policy on Endangered Languages'. In International Journal of Multicultural Societies.(2) University of Oxford.

Rubanza, Y 2002. Competition through English: The Failure of the Tanzanian Language Policy. In Prah Kwesi 2002 (ed.) Rehabilitating African Languages. Cape Town, CASAS .

Skutnabb-Kangas (2002) 'Why Should Linguistic Diversity be Maintained and Supported in Europe? Some Arguments'. Language policy division, Council of Europe, Strasbourg.

Skutnab Kangas, T. and Robert Phillipson (eds.). 1995. Linguistic Human Rights. Overcoming Linguistic Discrimination. Berlin: Mouton De Gruyter.

Stroud, Christopher. 2001. "African Mother-tongue Programmes and the Politics of Language: Linguistic Citizenship versus Linguistic Human Rights". Journal of Multilingual and Multicultural Development. Vol. 22, no. 4, 2001, 339-355

UNESCO 2001. Universal Declaration of Cultural Diversity, the Rosen, Publishing Group Inc-New York

UNESCO 2003a. Ad hoc Expert Group on Endangered Languages. Language Vitality and Endangerment. Ms. Paris: UNESCO.

UNESCO 2003b. Education in a Multilingual World. Paris: UNESCO Position Document.

UNESCO 2003c. Partager un monde de différence. La diversité linguistique, culturelle et biologique de la terre. UNESCO-TERRALINGUA: Fond Mondial pour la Nature, Paris.

Yagmur, Kutlay and Martin Ehale 2011. Tradition and Innovation in Ethnolinguistic Vitality Theory, Journal of Multilingual and Multicultural Development. Vo.32, No. 2, 2011.

Zaidi, Abbas 2011. Ethno linguistic Vitality of Punjabi in Pakistan, a GIDS Approach journal of languages and literature, Vol. 1, 2011. 
(C) 2012 The Author(s). Licensee IntechOpen. This is an open access article distributed under the terms of the Creative Commons Attribution 3.0 License, which permits unrestricted use, distribution, and reproduction in any medium, provided the original work is properly cited. 